\title{
Socializing in an Open Drug Scene: The relationship Between Access to Private Space and Drug-Related Street Disorder
}

\author{
Kora DeBeck ${ }^{1}$, Evan Wood ${ }^{1,2}$, Jiezhi Qi ${ }^{1}$, Eric Fu ${ }^{1}$, Doug McArthur ${ }^{3}$, Julio Montaner ${ }^{1,2}$, and \\ Thomas Kerr ${ }^{1,2}$ \\ ${ }^{1}$ British Columbia Centre for Excellence in HIV/AIDS \\ 2 Division of AIDS, Department of Medicine, University of British Columbia \\ ${ }^{3}$ School of Public Policy, Simon Fraser University
}

\begin{abstract}
Background-Limited attention has been given to the potential role that the structure of housing available to people who are entrenched in street-based drug scenes may play in influencing the amount of time injection drug users (IDU) spend on public streets. We sought to examine the relationship between time spent socializing in Vancouver's drug scene and access to private space.

Methods-Using multivariate logistic regression we evaluated factors associated with socializing (three+ hours each day) in Vancouver's open drug scene among a prospective cohort of IDU. We also assessed attitudes towards relocating socializing activities if greater access to private indoor space was provided.
\end{abstract}

Results-Among our sample of 1114 IDU, $43 \%$ fit our criteria for socializing in the open drug scene. In multivariate analysis, having limited access to private space was independently associated with socializing (adjusted odds ratio: $1.80,95 \%$ confidence interval: $1.28-2.55$ ). In further analysis, $65 \%$ of 'socializers' reported positive attitudes towards relocating socializing if they had greater access to private space.

Conclusion-These findings suggest that providing IDU with greater access to private indoor space may reduce one component of drug-related street disorder. Low-threshold supportive housing based on the 'housing first' model that include safeguards to manage behaviors associated with illicit drug use appear to offer important opportunities to create the types of private spaces that could support a reduction in street disorder.

\section{Keywords}

injection drug use; street disorder; drug scenes; supportive housing; prospective cohort study

\section{Introduction}

Drug-related street disorder, including public drug use and intoxication and loitering in public areas, negatively impacts neighborhood businesses and surrounding communities and

(C) 2011 Elsevier Ireland Ltd. All rights reserved.

Send correspondence to: Thomas Kerr BC Centre for Excellence in HIV/AIDS 608-1081 Burrard Street, Vancouver, B.C. CANADA V6Z 1 Y6 Tel: (604) 806-9116 uhri-tk@cfenet.ubc.ca.

Publisher's Disclaimer: This is a PDF file of an unedited manuscript that has been accepted for publication. As a service to our customers we are providing this early version of the manuscript. The manuscript will undergo copyediting, typesetting, and review of the resulting proof before it is published in its final citable form. Please note that during the production process errors may be discovered which could affect the content, and all legal disclaimers that apply to the journal pertain. 
can detract from the enjoyment of public spaces (Cusick and Kimber, 2007; Johnson et al., 1990; Skogan, 1990). Drug-related street disorder is a burden for law enforcement agencies and recent evidence suggests that exposure to street-based drug scenes poses risks to individual drug users (DeBeck, 2011; Messner et al., 2007; Zimmer, 1990). Policy responses to address street disorder in open drug scenes have, to date, largely relied on law enforcement measures to deter disorderly behavior in public settings (Aitken et al., 2002; Fagan and Davies, 2000; Zimmer, 1990).

In some areas with concentrated drug and street disorder problems, police agencies have initiated crackdown campaigns, which involve targeting policing efforts on drug-related street disorder (Aitken et al., 2002; Fagan and Davies, 2000; Zimmer, 1990). Increased police presence and patrol and arresting individuals for disorderly behaviors are some key features of crackdown campaigns (Aitken et al., 2002). In Canada, some provinces have also introduced legislation specific to street disorder. For instance, legislation in several Canadian provinces (i.e., the 'Safe Streets Act' in Ontario and British Columbia) provides law enforcement officers with additional tools to limit soliciting in public locations (Collins and Blomley, 2003; Hermer and Mosher, 2002). Although law enforcement measures have been found to reduce the visual presence of street disorder (Koper, 1995; Sherman, 1990; Weisburd and Green, 1995), these effects are typically short-lived and are often associated with unintended negative consequences (Wood et al., 2004). These include displacing disorderly behavior to surrounding areas and separating illicit drug users from health and social services (Clear, 2007; Cooper et al., 2005; Dixon, 2002; Hermer and Mosher, 2002; Kerr et al., 2005; Rhodes et al., 2003a; Roberts, 1998; Small et al., 2006; Wood et al., 2003). Given the apparent limitations of law enforcement based approaches, there is a need to identify novel interventions with potential to address street disorder.

To guide our analyses of drug-related street disorder we drew on Rhodes' 'Risk Environment Framework' (Rhodes, 2002; Rhodes et al., 2003b). Rhodes suggests that social, structural and environmental conditions constitute a 'risk environment' that mediates individual behavior (Rhodes, 2002; Rhodes et al., 2003b). In turn, individual behavior should be viewed in the context or environment in which it occurs. From this perspective, responding to risky and undesirable practices associated with illicit drug use involves altering the 'risk environment' by addressing relevant social, structural and environmental factors. Examples of key structural factors include economic conditions (e.g., employment opportunities), laws (e.g., prohibition of drugs), local policing practices, and social policies such as access to low-threshold and supportive housing (Rhodes, 2009).

To date, policy-makers and researchers have given limited consideration to the potential role that the structure of the housing available to people who are entrenched in drug scenes may play in influencing the amount of time individuals spend on public streets. Restrictions on socializing in residential spaces, either through space constraints or regulations that impose barriers to having guests in private venues may inadvertently contribute to street disorder.

Therefore, we sought to examine the relationship between time spent socializing in Vancouver's open drug scene and access to private space among local injection drug users (IDU). We hypothesized that spending time socializing in the open drug scene would be associated with having limited access to private space. We also sought to characterize drug use patterns and risk factors associated with socializing in Vancouver's open drug scene, as well as assess whether IDU would prefer access to private indoor space. 


\section{Methods}

\subsection{Data}

Data for this study was obtained from the Vancouver Injection Drug Users Study (VIDUS), an open prospective cohort that began enrolling IDU through street outreach and selfreferral in May 1996. This study has been described in detail previously (Wood et al., 2003; Wood et al., 2004). In brief, to be eligible, participants must reside in the Greater Vancouver Regional District, have injected illicit drugs in the previous month, and provide written informed consent. At enrollment and on a bi-annual basis, participants complete an interviewer-administered questionnaire and visit with study nurses who take a blood sample for serologic testing. At each study visit, participants are provided with a stipend ( $\$ 20 \mathrm{CDN})$ for their time. The study has received ethical approval from St. Paul's Hospital and the University of British Columbia's Research Ethics Board. The present analyses are restricted to those participants seen for study follow-up during the period of June 2008 to June 2009 as measures for key variables of interest are available only for this period. If individuals were seen for multiple study follow-up visits during this study period only data from their first visit was used.

\subsection{Socializing in Vancouver's open drug scene and access to private space}

In our first analysis, the outcome of interest was spending time socializing in Vancouver's open drug market scene. To measure 'socializing' we asked respondents to estimate the average number of hours they spend on the street each day, and then we asked them to specify how many of those hours on average were spent socializing. Because we were interested in socializing in an open drug scene as an indicator of drug-related street disorder we wanted to ensure that we were identifying individuals who spent significant amounts of time in this environment. We therefore used two criteria to define 'socializing:' firstly, we identified the median number of hours participants reported socializing on the street in an average day, which was three hours, and used a median split to create our dependent variable; secondly, we included only individuals who either resided in or frequently visited (at least two times per week) Vancouver's drug use epicenter, which is a well defined and described area of the city known as the Downtown Eastside (DTES) (Wood et al., 2004). This helped to ensure that we were identifying individuals who were likely contributing to street disorder in Vancouver's open drug market scene (and not simply spending time outdoors in non-drug market scenes and venues).

The primary explanatory variable of interest for this first analysis was having 'limited private space for socializing.' Individuals who answered "no" to the question: "Do you have a private indoor space for socializing with friends and acquaintances?" were included in this category. Because we wanted to include an objective marker in our measure of access to private space for socializing, we also considered the number of guests individuals were allowed to have in their residence at one time, including all reports of being allowed less than three guests at one time in the 'limited private space' category -even if respondents initially reported "yes" to having private space for socializing. Similarly, if other significant barriers to having guests in their residence were reported, these individuals were also included in the category of having 'limited private space for socializing.' Significant barriers included 'guest fees' (typically \$5-10 per guest), time restrictions on visitors, restrictions on the appearance of guests (e.g., visitors must be well groomed, can not appear intoxicated) and the requirement that guests must show picture identification. Participants reporting "yes" to having access to private space and reported none of the above restrictions to having guests were included in the comparison group. 
To determine whether there was a significant relationship between socializing in an open drug scene and having limited access to private space we a priori selected a range of secondary explanatory variables that we hypothesized might be associated with both socializing in an open drug scene and having access to private space. Variables that were unlikely to be associated with both of these outcomes were not considered in this model. Secondary explanatory factors that were considered included the following sociodemographic factors: age (per year older); gender (female vs. male); Aboriginal ancestry (yes vs. no); high school education (yes vs. no), regular employment (yes vs. no), ever testing positive for HIV (which in our setting might influence the types of housing options available) (yes vs. no), and living in Vancouver's drug use epicenter, the Downtown Eastside (DTES) (yes vs. no). Individual-level risk and protective factors that were considered included: sex trade involvement, defined as exchanging sex for money, shelter, drugs or other commodities (yes vs. no); participation in drug dealing (yes vs. no); participation in any addiction treatment program (yes vs. no); daily cocaine injection (yes vs. no); daily heroin injection (yes vs. no); daily crack cocaine smoking (yes vs. no); and binge drug use (yes vs. no). Binge drug use was based on the question: "In the past six months, did you go on runs or binges (that is, when you injected drugs, or used non-injection drugs, more than usual)"? The terms "runs" and "binges" are generally well understood by local IDU and indicate engaging in higher intensity drug use for a period of time typically ranging from a few days to a few weeks (Miller et al., 2006). Structural-level factors included having been incarcerated (yes vs. no). Unless otherwise stated, socio-demographic, individual and structural level factors refer to the previous six-month period. To account for a potential seasonal influence on the amount of time individuals spend on the street socializing, we also included a categorical variable representing the month that participants completed our study questionnaire. This ensured that our multivariate analysis was adjusted for seasonal variation in responses.

\subsection{Socializing in Vancouver's open drug scene and risk factors}

In our second analysis we sought to identify drug use patterns and risks associated with socializing in Vancouver's open drug scene. Our outcome of interest remained 'socializing in Vancouver's open drug scene.' Basic socio-demographic variables of interest included: age (per year older); and gender (female vs. male). We also considered the same individuallevel risk factors considered in the first analysis, which were: sex work, drug dealing, addiction treatment, daily cocaine injection, daily heroin injection, daily crack cocaine smoking, and binge drug use. In addition, we considered the following new risk factors: non-fatal overdose (yes vs. no); syringe sharing, defined as borrowing or lending syringes already used by someone else to inject drugs (yes vs. no); having multiple sex partners (yes vs. no); encounters with police in the last month, defined as being questioned, searched or stopped by police (yes vs. no); and being a victim of violence defined as being physically assaulted (yes vs. no). We also sought to assess the relationship between socializing and housing status. To do this we created a categorical variable for housing with 'stable housing' as the reference. Categories for housing status were mutually exclusive and based on where participants were residing at the time of the interview. The categories considered included: stable housing, defined as living in a house or apartment; single room occupancy (SRO), defined as a single room in a hotel; shelter, defined as sleeping in temporary shelters for homeless individuals (which are typically only open at night); no fixed address, defined as having no stable residence, including sleeping on the street as well as staying with friends or acquaintances on a short term basis, i.e., 'couch surfing'; and 'other' which included living in an addiction treatment centre or recovery house, jail or prison, and all other situations that did not fit into the above categories. This analysis also included a categorical variable representing the month that participants completed our study questionnaire to adjust for any seasonal variation in responses. 


\subsection{Factors associated with positive attitudes towards relocating to private indoor locations}

In our final analysis, we sought to assess and identify factors associated with having a positive attitude towards relocating socializing activities to indoor private locations if such spaces were made available. This analysis was restricted to participants who reported socializing in an open drug scene and who have limited access to private indoor space. To measure attitudes towards relocating we asked participants "Would you spend less time socializing on the street if you had a private indoor space (or more private indoor space) for socializing with friends and acquaintances?" The geographic location of where private indoor space might be located was not specified and no additional description of the type of private space was given. Variables of interest for this analysis included all variables considered in either the first or second analyses with the exception of high school education, 'limited access to private space' and DTES residency. The latter two variables were excluded because they were so closely linked to the inclusion criteria for this analysis. One additional factor that we considered was the level of socializing, which was defined as a continuous variable based on the number of hours participants reported socializing in the open drug scene. Unless otherwise stated, all drug use and behavioral variables refer to the previous six-month period. As in analyses one and two, a categorical variable representing the month that participants completed our study questionnaire was also included in the multivariate analysis to adjust for any seasonal variation in responses.

\subsection{Statistical Analyses}

In analysis one, to assess the relationship between socializing and access to private space, as a first step we conducted univariate analyses for our primary and secondary outcomes of interest stratified by socializing in an open drug scene. We used Pearson's chi-square test for dichotomous variables and the Mann-Whitney test for continuous variables. To fit our multivariate model, we used a modified version of a backwards selection process previously described by Maldonado and Greenland (1993) and Rothman and Greenland (1998). We began with all outcomes of interest in a full model. To ensure that socio-economic status was appropriately considered, the following socio-demographic factors remained in the multivariate model: age, gender, Aboriginal ancestry, high school education, and recent employment. Since 'limited access to private space' was our primary variable of interest, it also remained in the multivariate model. For all other factors we used backward selection and removed all variables that were associated with the dependent variable at $p>0.05$. The final model, referred to as 'Model 1', included the above-mentioned socio-demographic factors, 'limited access to private space,' and all remaining secondary explanatory variables.

For analyses two and three, we used logistic regression to determine factors associated with our outcomes of interest, which were socializing in Vancouver's open drug scene (analysis two, Model 2) and attitudes towards relocating to private indoor spaces (analysis three, Model 3). In univariate analyses, categorical explanatory variables were analyzed using Pearson's chi-square test and continuous variables were analyzed using the Mann-Whitney test. Fisher's exact test was used when one or more of the cell counts was less than or equal to five. To evaluate factors independently associated with our outcomes of interest, we used Akaike information criterion (AIC) with the best subset selection procedure. This provided a computationally efficient method to screen all possible combinations of candidate variables and identify the model with the best overall fit as indicated by the lowest AIC value (Shtatland et al., 2002). All statistical analyses were performed using SAS software version 9.1 (SAS, Cary, NC). All p-values are two sided. 


\section{Results}

During the study period, a total of 1,114 participants completed follow-up visits, including 393 (35\%) women and 396 (36\%) persons who identified as being of Aboriginal ancestry. The median age of all participants was 44 years (interquartile range $[\mathrm{IQR}]=38-50$ ), and the current housing statuses of study participants are displayed in Figure 1. Among our sample of 1,114 participants, the median number of hours spent socializing in the open drug scene was 3 (IQR=1-8) and 475 individuals (43\%) fit the criteria for socializing in the open drug scene. The characteristics of the study sample stratified by socializing in the open drug scene are presented in Table 1 .

The univariate analyses of associations between socializing in the open drug scene and socio-demographic, individual, and structural level factors are presented in Table 2. Having limited access to private space for socializing was significantly associated with socializing in the open drug scene (Odds Ratio [OR] = 2.85, 95\% Confidence Interval [CI]: 2.11-3.86). The results of the final multivariate logistic regressions for Model 1 and Model 2 are also shown in Table 2.

In Model 1 the primary explanatory variable, 'limited access to private space,' remained independently associated with socializing in the open drug scene (Adjusted Odds Ratio $[\mathrm{AOR}]=1.80,95 \% \mathrm{CI}: 1.28-2.55$ ) after adjusting for key socio-demographic factors, as well as Downtown Eastside (DTES) residency, drug dealing, engagement in any addiction treatment, daily crack cocaine smoking, and binge drug use.

In Model 2, after adjusting for drug dealing, multiple sex partners and having encounters with police, factors positively associated with socializing included daily crack smoking, binge drug use, Aboriginal ancestry, and the following housing statuses: living in a single room occupancy hotel, shelter, and having no fixed address. Engagement with addiction treatment and syringe sharing were negatively associated with socializing.

In the third analysis, $254(65 \%)$ of the 390 participants that reported having limited access to private space and socializing in the open drug scene also reported positive attitudes towards relocating socializing if they were provided with more access to private indoor space. The characteristics of these individuals stratified by positive attitudes toward relocating to private indoor spaces are presented in Table 3. The univariate and multivariate analyses of associations between positive attitudes towards relocating and variables of interest are also presented in Table 3. In the multivariate analysis, Model 3, when compared to participants with stable housing, the no fixed address category was over eight times more likely to have positive attitudes towards relocating socializing. Individuals living in single room occupancy hotels (SROs) and shelters were two and six times more likely to have positive attitudes respectively. Aside from current housing status, daily heroin injection was the only other factor that was significantly associated with positive attitudes towards relocating (AOR $=1.89,95 \%$ CI: $1.05-3.38)$.

\section{Discussion}

In the present study we found that, among local injection drug users, having limited private space was significantly associated with spending an average of three or more hours per day socializing in the open drug scene. This association persisted after adjustment for a range of potential confounding factors. In our second analysis, we found current housing status was strongly associated with socializing in the open drug scene. Specifically, those with no fixed address were most likely to report socializing in the open drug scene, followed by individuals living in a shelter, and individuals living in a single room occupancy hotel. Binge drug use and daily crack cocaine use were also positively associated with socializing 
in the open drug scene, while syringe sharing and engagement with addiction treatment were negatively associated with socializing in this environment. The majority (65\%) of those who had limited access to private space and spent significant time socializing in the open drug scene reported positive attitudes towards relocating socializing away from the open drug scene if they were provided with access to more private spaces. Not surprisingly, when compared to IDU who lived in stable housing, study participants who lived in single room occupancy hotels (SROs), shelters and had no fixed address were significantly more likely to socialize in the open drug scene and were significantly more likely to have positive attitudes towards relocating. It is notable that no risk behaviors were negatively associated with reporting positive attitudes towards relocating. This suggests that policy initiatives that involve increasing access to private space could be expected to have an impact even among high-risk and high intensity drug users.

These findings are consistent with existing data highlighting that open drug scenes and congregations of drug users often exist in locations where rates of homelessness and unstable housing are a problem among drug using populations (Broadhead et al., 2002; Shlay and Rossi, 1992; Skogan, 1990). Although the links between homelessness and street disorder have been previously described (Broadhead et al., 2002; DeBeck et al., 2009; Navarro and Leonard, 2004), to our knowledge, our study is the first to highlight that a lack of access to private space is likely playing a role in generating street disorder in open drug scenes.

A central implication of these findings is that providing street-involved drug users with areas where they can socialize in comfort and privacy may offer the potential to reduce a component of drug-related street disorder. The benefits of relocating street-involved individuals to indoor locations by providing housing or creating alternative venues for socializing appears particularly valuable given the burden that drug-related street disorder poses for law enforcement agencies and surrounding communities, as well as potential harms that exposure to drug scenes poses to drug users themselves (DeBeck et al., 2009; Zimmer, 1990; DeBeck et al., 2011).

Although it can be challenging to provide housing for some chaotic drug using individuals, there is a growing body of literature which suggests that approaches such as the "housing first" model, which provide drug using individuals with independent stable housing regardless of their drug use practices, are more successful than abstinence-based supportive housing in retaining and stabilizing active drug users (Greenwood et al., 2005; Larimer et al., 2009; Tsemberis et al., 2004). Our study suggests that if these housing models can accommodate active drug users and provide housing with social spaces for this population, they could play an important role in the reduction of street disorder. It is important to recognize, however, that there are potential unintended harms that might result from relocating active drug users into private indoor locations, particularly if these locations are unsupervised and do not have safeguards to manage behaviors that might be associated with active drug use, such as drug overdose events or illicit drug dealing which is often linked with violence given the unregulated nature of the illicit drug market (Erickson, 2001).

To address risks associated with active drug use, there may be a role for supervised drug consumption facilities integrated into supportive housing models. Indeed, the integration of a 'harm reduction' supervised injecting room in one supportive housing facility for people with HIV/AIDS in Vancouver has been shown to be successful in reducing risky drug use practices on the premises (Krusi et al., 2009). Furthermore, in our study setting, a number of non-profit housing societies have been able to successfully provide supportive housing for individuals who actively use drugs and have been able to manage behaviors associated with illicit drug use (Atira Women's Resource Society, 2010; Gurstein and Small, 2005). Within 
these models, special consideration is given to ensure that residents' health and physical security needs are met. In particular, measures are taken to accommodate and address the risks associated with drug use, including drug use which normally would take place in outdoor locations within the open drug scene (Gurstein and Small, 2005).

Although there is now a wide literature suggesting that low-threshold housing options in line with a housing first model successfully support and retain individuals with high intensity addiction and, as our study indicates, have potential to reduce street disorder, low-threshold housing currently makes up only a small proportion of existing housing units in our study setting (Eby and Misura, 2006; Housing Centre Community Services Group, 2007). Our data add to existing evidence highlighting the need to increase the supply of low-threshold supportive housing that includes safeguards to manage behaviors associated with active illicit drug use including drug overdose events and drug dealing and accompanying risks for violence (Martinez and Burt, 2006; Salit et al., 1998).

There are a number of limitations in this study. Firstly, Vancouver's housing situation and open drug scene have unique features that may limit the generalizability of these findings. However, drug-related street disorder and lack of supportive housing for drug using populations are issues in many other urban settings and therefore the findings of this study may be relevant to other areas. Secondly, while our definition of the variable "limited private space for socializing' included individuals who had no access to private space, it also included individuals who had access to private space, but who were restricted to having less than three guests visit at one time. Despite the restriction, it should be noted that these individuals could socialize in their own private space. Thirdly, a number of our measures were based upon self-report data and are therefore vulnerable to recall bias and socially desirable responding. In this study, issues with recall could have resulted in an over- or underestimation of the number of hours spent on the street socializing, suggesting that if recall issues were present they would have biased our result towards the null. If socially desirable responding was an issue, we suspect this response bias would have led to an underreporting of the number of hours spent on the street, which in turn may have led to an underestimation of the association between access to private space and socializing in the open drug scene. Finally, our third analysis relied on participants' attitudes and does not represent actual behavior change. There are likely multiple factors that contribute to socializing in public spaces and providing private space may not change this behavior.

In summary, our data indicate that a lack of access to private space among people who use drugs may contribute to street disorder in open drug scenes. Study findings further suggest that increasing access to private spaces that accommodate socializing among active drug users and include safeguards to manage behaviors associated with active illicit drug use has potential to reduce one component of street disorder. Low-threshold supportive housing approaches based on the housing first model appear to offer important opportunities to meet these objectives.

\section{References}

Aitken C, Moore D, Higgs P, Kelsall J, Kerger M. The impact of a police crackdown on a street drug scene: evidence from the street. Int. J. Drug Policy. 2002; 13:189-198.

Atira Women's Resource Society. [August 11, 2010] Housing. http://www.atira.bc.ca/housing.html

Broadhead R, Kerr T, Grund JP, Altice F. Safer injection facilities in North Americas: their place in public policy and health initiatives. J. Drug Issues. 2002; 32:329-356.

Clear, TR. Imprisoning Communities: How Mass Incarceration Makes Disadvantaged Neighborhoods Worse. Oxford University Press; New York: 2007. 
Collins D, Blomley N. Private needs and public space: politics, poverty, and anti-panhandling by-laws in Canadian cities. In: New Perspectives on the Public-Private Divide. Law Commission of Canada. 2003; 2003:40-67.

Cooper H, Wypij D, Krieger N. Police drug crackdowns and hospitalisation rates for illicit-injectionrelated infections in New York City. Int. J. Drug Policy. 2005; 16:150-160.

Cusick L, Kimber J. Public perceptions of public drug use in four UK urban sites. Int. J. Drug Policy. 2007; 18:10-17. [PubMed: 17689339]

DeBeck K, Wood E, Zhang R, Buxton J, Montaner J, Kerr T. A dose-dependent relationship between exposure to a street-based drug scene and health-related harms among people who use injection drugs. J. Urban Health. May 2.2011 [Epub ahead of print].

DeBeck K, Small W, Wood E, Li K, Montaner J, Kerr T. Public injecting among a cohort of injecting drug users in Vancouver, Canada. J. Epidemiol. Community Health. 2009; 63:81-86. [PubMed: 18628270]

Dixon D, Maher L. Anh hai: policing, culture and social exclusion in a street heroin market. Policing Society. 2002; 12:93-110.

Eby, D.; Misura, C. Cracks in the Foundation: Solving the Housing Crisis in Canada's Poorest Neighbourhood. Pivot Legal Society; Vancouver, BC: 2006. Available at: http://www.pivotlegal.org/pdfs/CracksinFoundation.pdf

Erickson, P. Sensible Solutions to the Urban Drug Problem. Fraser Institute Digital Publications; 2001. Drugs, Violence and Public Health: What does Harm Reduction Approach have to Offer?. Available at: http://oldfraser.lexi.net/publications/books/drug_papers/UDErickson.pdf

Fagan J, Davies G. Street stops and broken windows: terry, race and disorder in New York City. Fordham Urban Law J. 2000; 28:457.

Greenwood RM, Schaefer-McDaniel NJ, Winkel G, Tsemberis SJ. Decreasing psychiatric symptoms by increasing choice in services for adults with histories of homelessness. Am. J. Community Psychol. 2005; 36:223-238. [PubMed: 16389497]

Gurstein P, Small D. From housing to home: reflexive management for those deemed hard to house. Housing Stud. 2005; 20:717-735.

Hermer, J.; Mosher, J., editors. Disorderly People: Law and the Politics of Exclusion in Ontario. Fernwood Publishing; Halifax: 2002.

Housing Centre Community Services Group. 2007 Survey of Low-Income Housing in the Downtown Core. City of Vancouver; Vancouver, Canada: 2007. Available at: http://vancouver.ca/ctyclerk/cclerk/20070712/documents/csb5complete.pdf

Johnson BD, Williams T, Dei KA, Sanabria H. Drug abuse in the inner city: impact on hard-drug users and the community. Crime Justice Rev. Res. 1990; 13:9.

Kerr T, Small W, Wood E. The public health and social impacts of drug market enforcement: a review of the evidence. Int. J. Drug Policy. 2005; 16:210-220.

Koper CS. Just enough police presence: reducing crime and disorderly behavior by optimizing patrol time in crime hot spots. Justice Q. 1995; 12:649.

Krusi A, Small W, Wood E, Kerr T. An integrated supervised injecting program within a care facility for HIV-positive individuals: a qualitative evaluation. AIDS Care. 2009; 21:638-644. [PubMed: 19444673]

Larimer ME, Malone DK, Garner MD, Atkins DC, Burlingham B, Lonczak HS, Tanzer K, Ginzler J, Clifasefi SL, Hobson WG, Marlatt GA. Health care and public service use and costs before and after provision of housing for chronically homeless persons with severe alcohol problems. JAMA. 2009; 301:1349-1357. [PubMed: 19336710]

Maldonado G, Greenland S. Simulation study of confounder-selection strategies. Am. J. Epidemiol. 1993; 138:923-936. [PubMed: 8256780]

Martinez TE, Burt MR. Impact of permanent supportive housing on the use of acute care health services by homeless adults. Psychiatr. Serv. 2006; 57:992-999. [PubMed: 16816284]

Messner S, Galea S, Tardiff K, Tracy M, Bucciarelli A, Piper T, Frye V, Vlahov D. Policing, drugs, and the homicide decline in New York City in the 1990s. Criminology. 2007; 45:30. 
Miller C, Kerr T, Frankish J, Spittal P, Li K, Schechter M, Wood E. Binge drug use independently predicts HIV seroconversion among injection drug users: implications for public health strategies. Subst. Use Misuse. 2006; 41:199-210. [PubMed: 16393742]

Navarro C, Leonard L. Prevalence and factors related to public injecting in Ottawa, Canada: implications for the development of a trial safer injecting facility. Int. J. Drug Policy. 2004; 15:275-284.

Rhodes T. The 'risk environment': a framework for understanding and reducing drug-related harm. Int. J. Drug Policy. 2002; 13:85-94.

Rhodes T, Mikhailova L, Sarang A, Lowndes CM, Rylkov A, Khutorskoy M, Renton A. Situational factors influencing drug injecting, risk reduction and syringe exchange in Togliatti City, Russian Federation: a qualitative study of micro risk environment. Soc. Sci. Med. 2003a; 57:39-54. [PubMed: 12753815]

Rhodes T, Lilly R, Fernández C. Risk factors associated with drug use: the importance of 'risk environment'. Drugs Educ. Prev. Policy. 2003b; 10:303-329.

Rhodes T. Risk environments and drug harms: a social science for harm reduction approach. Int. J. Drug Policy. 2009; 20:193-201. [PubMed: 19147339]

Roberts DE. Race, vagueness, and the social meaning of order-maintenance policing. J. Criminal Law Criminology. 1998; 89:775.

Rothman, KJ.; Greenland, S. Modern epidemiology. Lippincott Williams and Wilkins; New York: 1998.

Salit SA, Kuhn EM, Hartz AJ, Vu JM, Mosso AL. Hospitalization costs associated with homelessness in New York City. N. Engl. J. Med. 1998; 338:1734-1740. [PubMed: 9624194]

Sherman LW. Police crackdowns: initials and residual deterrence. Crime Justice Rev. Res. 1990; 12:1.

Shlay AB, Rossi PH. Social science research and contemporary studies of homelessness. Annu. Rev. Sociol. 1992; 18:129-160.

Shtatland, ES.; Cain, E.; Barton, MB. The Perils of Stepwise Logistic Regression and How to Escape Them Using Information Criteria and the Output Delivery System.. Proceedings from the 26th Annual SAS Users Group International Conference; 2001. p. 22-25.

Skogan, WG. Disorder and Decline: Crime and the Spiral of Decay in American Neighborhoods. Free Press; New York: 1990.

Small W, Kerr T, Charette J, Schechter MT, Spittal PM. Impacts of intensified police activity on injection drug users: evidence from an ethnographic investigation. Int. J. Drug Policy. 2006; 17:85-95.

Tsemberis S, Gulcur L, Nakae M. Housing first, consumer choice, and harm reduction for homeless individuals with a dual diagnosis. Am. J. Public Health. 2004; 94:651-656. [PubMed: 15054020]

Weisburd D, Green L. Policing drug hot spots: the Jersey City drug market analysis experiment. Justice Q. 1995; 12:711.

Wood E, Kerr T, Small W, Jones J, Schechter MT, Tyndall MW. The impact of a police presence on access to needle exchange programs. J. Acquir. Immune Defic. Syndr. 2003; 34:116-8. [PubMed: 14501805]

Wood E, Spittal P, Small W, Kerr T, Li K, Hogg R, Tyndall M, Montaner J, Schechter M. Displacement of Canada's largest public illicit drug market in response to a police crackdown. CMAJ. 2004; 170:1551-6. [PubMed: 15136548]

Zimmer L. Proactive policing against street-level drug trafficking. Am. J. Police. 1990; 9:43. 


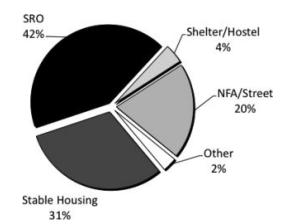

Figure 1. Housing status among injection drug users

SRO -'Single Room Occupancy' defined as a single room in a hotel; NFA -'No Fixed Address' 


\section{Table 1}

Characteristics of study sample stratified by socializing in Vancouver's open drug scene $(\mathrm{n}=1114)$

\begin{tabular}{|c|c|c|}
\hline \multirow[b]{2}{*}{ Characteristic } & \multicolumn{2}{|c|}{ Socializes in open drug scene ${ }^{a}$} \\
\hline & Yes $n=475, n(\%)$ & No $n=639, n(\%)$ \\
\hline \multicolumn{3}{|l|}{ Socio-Demographic Factors } \\
\hline \multicolumn{3}{|l|}{ Age (Median, IQR) ${ }^{b}$} \\
\hline Per year older & $44(37-49)$ & $45(38-50)$ \\
\hline Female Gender & $172(36)$ & $221(35)$ \\
\hline Aboriginal Ancestry & $196(41)$ & $200(31)$ \\
\hline High School Education & $214(45)$ & $326(51)$ \\
\hline Employment ${ }^{c}$ & $86(18)$ & $157(25)$ \\
\hline HIV Positive & $152(32)$ & $214(33)$ \\
\hline DTES Residency $^{c}$, & $415(87)$ & $357(56)$ \\
\hline \multicolumn{3}{|l|}{ Current Housing Status } \\
\hline Stable Housing & $78(16)$ & $270(42)$ \\
\hline Room in Hotel (SRO) & $225(47)$ & $245(38)$ \\
\hline Shelter & $19(4)$ & $20(3)$ \\
\hline No Fixed Address & $144(30)$ & $75(12)$ \\
\hline Other $^{e}$ & $9(2)$ & $29(5)$ \\
\hline \multicolumn{3}{|c|}{ Individual-Level Risk and Protective Factors } \\
\hline Sex Trade ${ }^{c}$ & $68(14)$ & $53(8)$ \\
\hline Drug Dealing ${ }^{c}$ & $184(39)$ & $134(21)$ \\
\hline Any Addiction Treatment ${ }^{c}$ & $243(51)$ & $391(61)$ \\
\hline Daily Cocaine Injection ${ }^{c}$ & $53(11)$ & $45(7)$ \\
\hline Daily Heroin Injection ${ }^{c}$ & $120(25)$ & $97(15)$ \\
\hline Daily Crack Smoking ${ }^{c}$ & $260(55)$ & $187(29)$ \\
\hline Binge Drug Use ${ }^{c}$ & $233(49)$ & $198(31)$ \\
\hline Overdose (non-fatal) ${ }^{c}$ & $26(5)$ & $18(3)$ \\
\hline Syringe Sharing ${ }^{c}$ & $14(3)$ & $35(5)$ \\
\hline Multiple Sex Partners ${ }^{c}$ & $90(19)$ & $82(13)$ \\
\hline \multicolumn{3}{|l|}{ Structural-Level Factors } \\
\hline Limited Private Space $^{c}$ & $405(85)$ & $428(67)$ \\
\hline Recent Incarceration ${ }^{c}$ & $72(15)$ & $64(10)$ \\
\hline Police Encounters ${ }^{f}$ & $148(31)$ & $116(18)$ \\
\hline Victim of Violence $^{c}$ & $99(21)$ & $101(16)$ \\
\hline
\end{tabular}

Note: 
${ }^{a}$ Socializing in the open drug scene was defined as living in or frequenting Vancouver's drug use epicenter and spending on average three or more hours on the street each day socializing

${ }^{b}$ IQR=Inter Quartile Range

${ }^{c}$ Denotes activities or situations occurring in the previous 6 months

$d_{\text {'DTES' }}$ = 'Downtown Eastside', Vancouver's drug use epicenter

$e^{e}$ 'Other' includes the categories: 'treatment recovery', 'jail (prison)', and 'other'

$f$ Denotes activities or situations occurring in the previous month. 


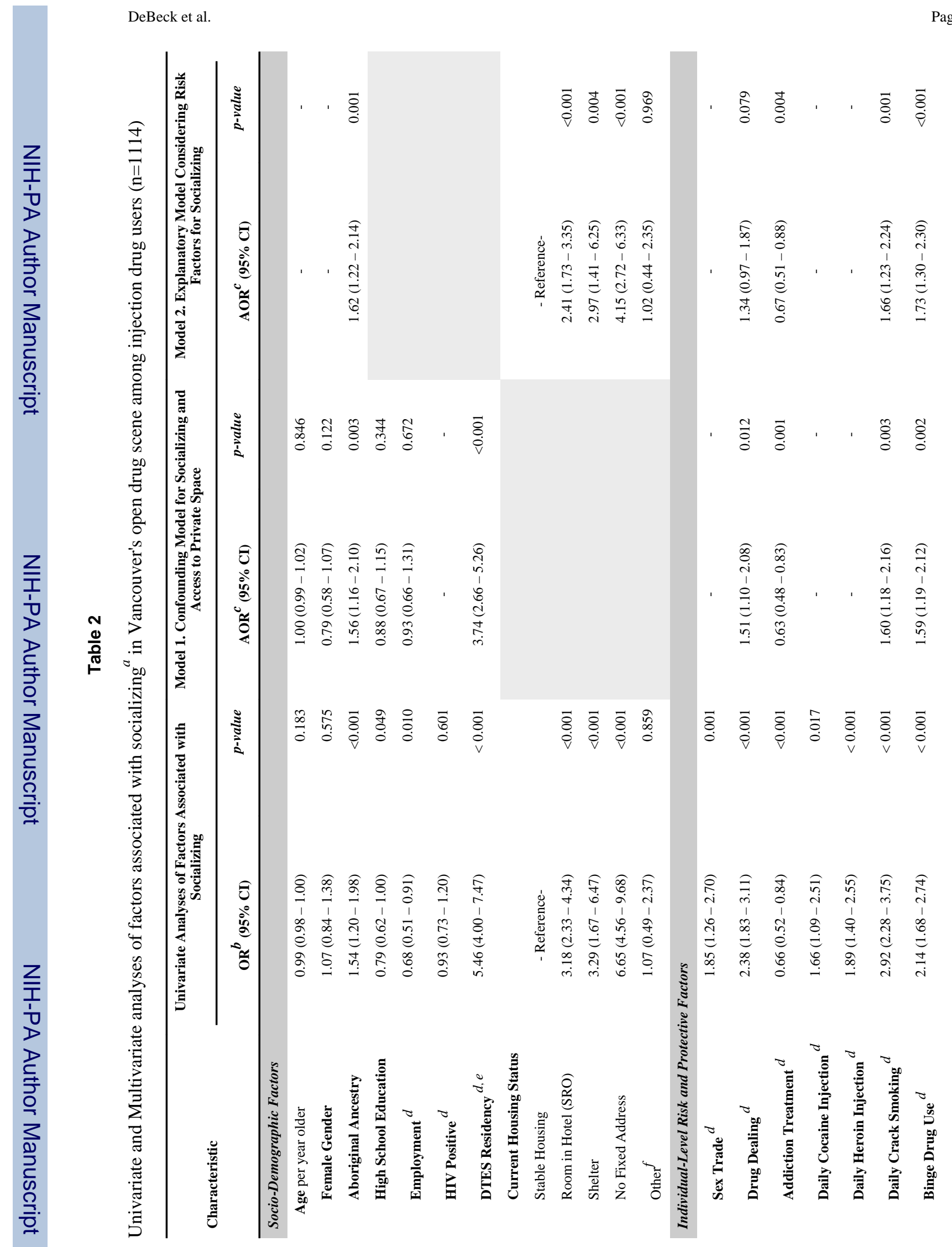

Drug Alcohol Depend. Author manuscript; available in PMC 2013 January 1. 
DeBeck et al.

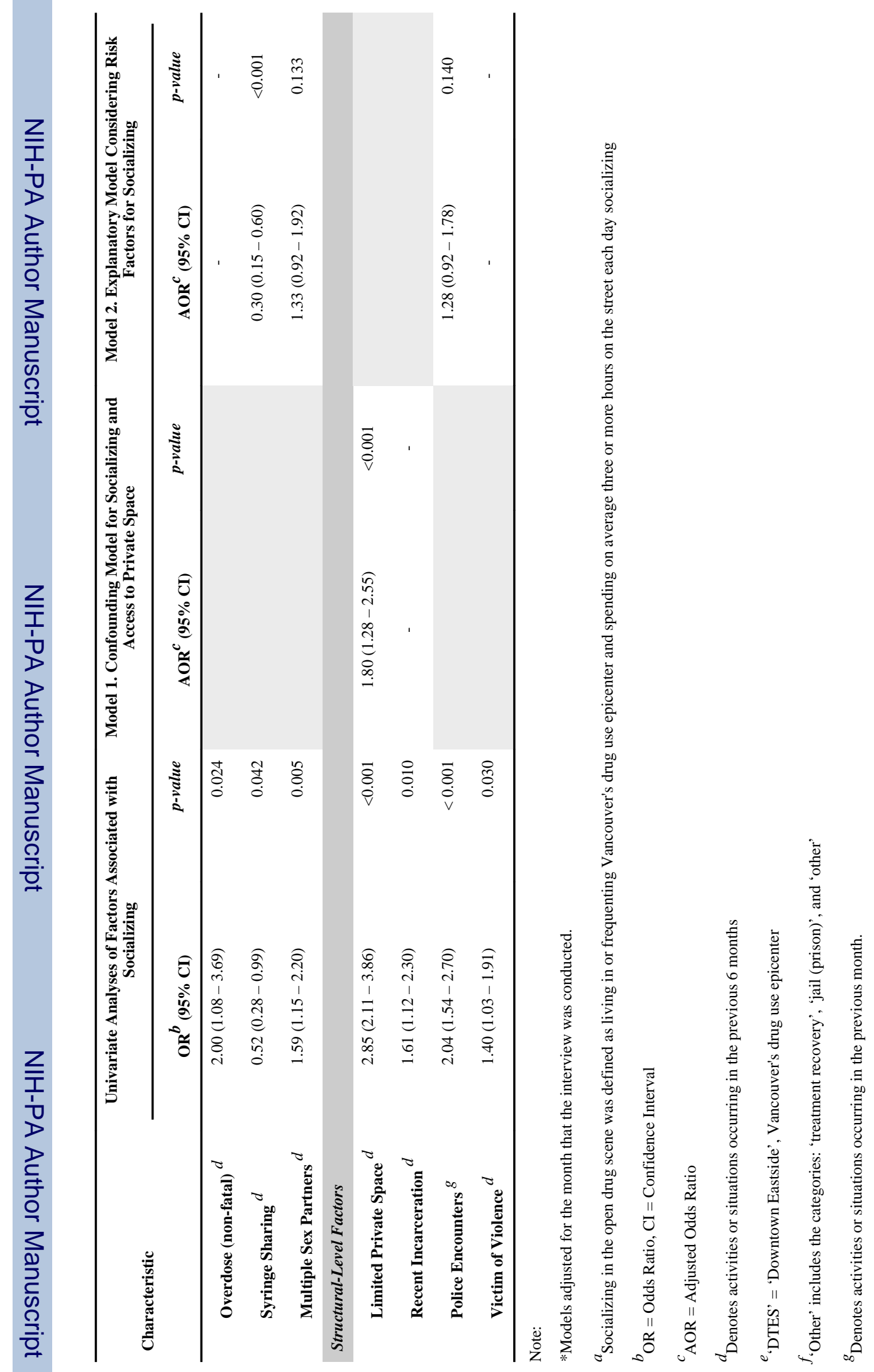




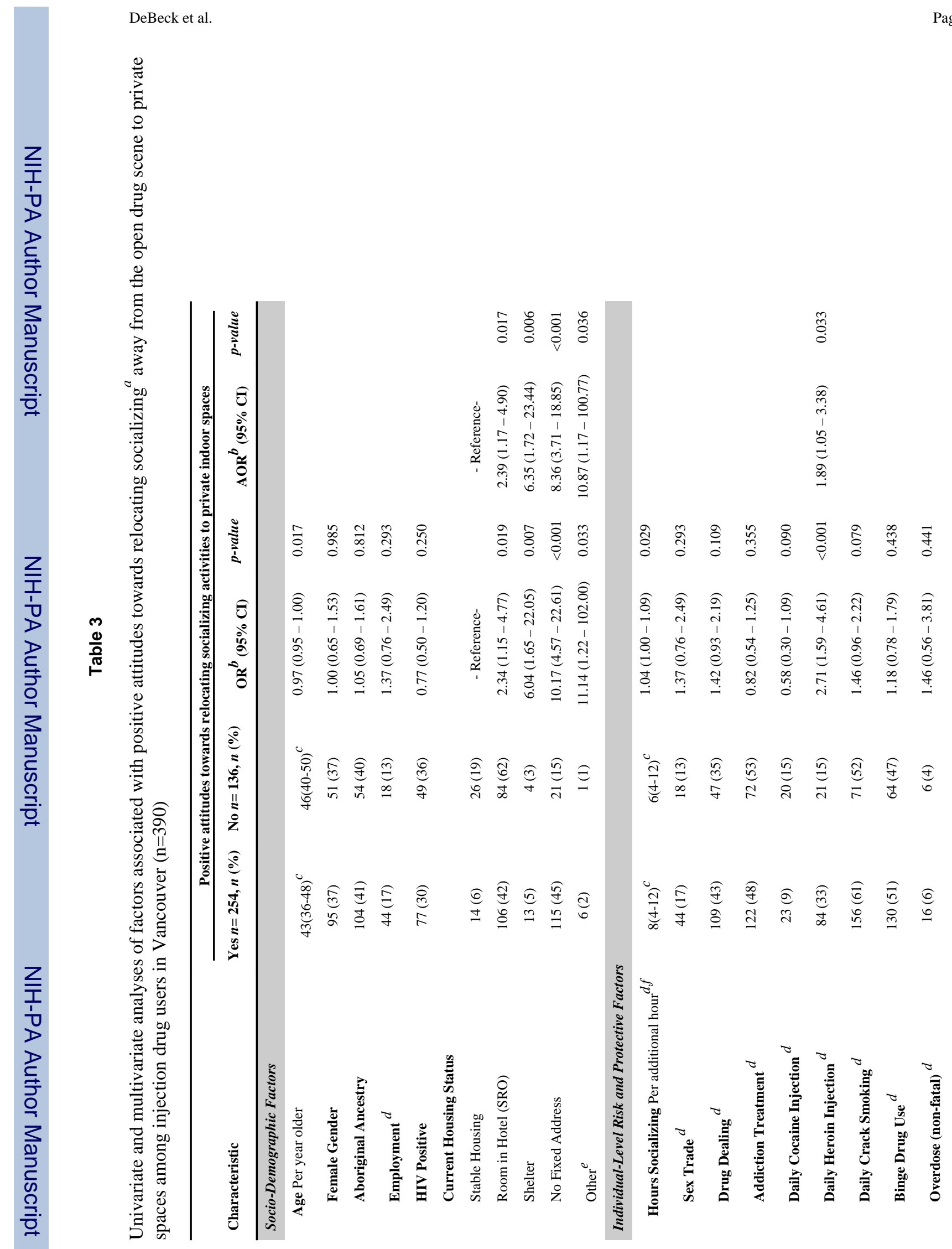

Drug Alcohol Depend. Author manuscript; available in PMC 2013 January 1. 


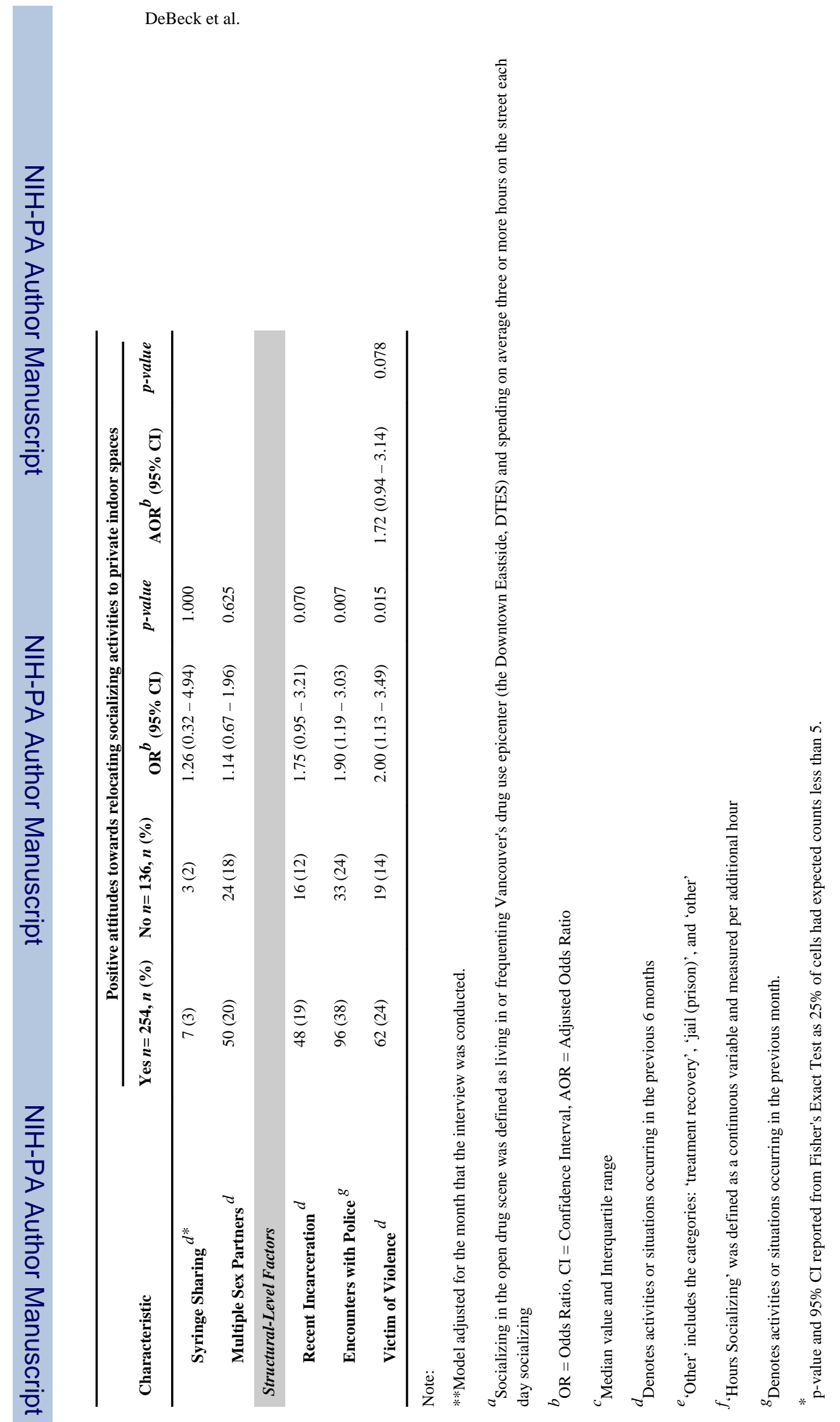

Page 17 